topic, this monograph by Jones is the best assessment to date of the variety of approaches being pursued towards such a goal. It is an eminently readable, well balanced account, extensively referenced for the specialist, yet with sufficient background information on the basic reproductive processes and immunological mechanisms to render it comprehensible to a diverse audience of advanced undergraduates and clinicians.

Those familiar with the series of position papers and reports of the WHO Task Force on Immunological Methods of Fertility Control will recognize at once the themes and variations presented in the book. Jones has clearly drawn heavily upon his long association with WHO and its scientific advisors to develop his personal stance. Although consideration is given to all the presently conceivable (and a few barely conceivable) reproductively unique components that might be used in the development of a contraceptive vaccine, emphasis is rightly given to those currently showing most promise - the $B$ subunit of the placental protein hormone chorionic gonadotrophin (hCG), diverse membrane and cytoplasmic elements of the spermatozoon, and the zona pellucida membrane encapsulating the oocyte and early embryo. Herein lies the declared primary aims and also the strength of Jones's book. Rather weaker, largely owing to an attempt to summarize unconfirmed or controversial data, are some minor sections devoted to immunological aspects of the nurmal reproductive process. Here there are a number of oversimplifications or unwarranted assertions, and the reader should turn to the more extensive and critical reviews to be found elsewhere in the literature.

Fertility regulation covers both inhibition and promotion of reproduction. Although the author is concerned largely with the former, about which far more is known, he gives brief consideration to the problems of overcoming those forms of infertility suspected of having an immunological basis. The recent approach to immunotherapy of recurrent spontaneous abortion is the only omission.

Although not everyone would share the author's optimism that a contraceptive vaccine is not too far round the corner, it would be excessively pessimistic to believe that the continuing endeavours in this field will not ultimately lead to a successful and acceptable procedure for fertility control. Warren Jones's monograph provides a welcome compass that will surely find a use in the hands of those wishing to determine the position and future direction of this most crucial practical application of reproductive immunology.

W.D. Billington is Reader in Reproductive Immunology and Director of the Reproductive Immunology Research Group at the Medical School, University of Bristol.

\section{Pioneering spirit in Brazil}

D.O. Hall

Energy from Alcohol: The Brazilian Experience.

By Harry Rothman, Rod Greenshields and Francisco Rosillo Callé.

University Press of Kentucky: 1983. Pp.187. \$20. Published in Britain under the title The Alcohol Economy: Fuel Ethanol and the Brazilian

Experience. Frances Pinter, 113.75.

LEAD could be removed from petrol tomorrow if the petrol was blended with alcohol at a $10 \%$ or greater concentration - with no harm to conventional engines because of the inherent octane-boosting properties of alcohol. The Brazilians now blend all their petrol with alcohol produced from sugarcane at concentrations of up to $20 \%$, while the Zimbabweans use $15 \%$ and the Americans use a $10 \% \mathrm{mix}$ to produce high-octanes.

In Brazil alcohol has been added to petrol since about 1930. The proportion used has varied depending on the state of the world sugar market and Government directives, and it is only since a concerted national programme was started in 1975 that a $20 \%$ alcohol blend has been the upper limit for all the petrol sold. !n addition there are now about 750,000 cars running on pure $(95 \%)$ alcohol, manufactured by the five major international car makers who produce over a million cars per year, and are currently selling 40,000 of the popular pure-alcohol cars per month.

The Brazilian experience with alcohol is very readably portrayed in this book which gives an excellent thumbnail sketch of what has happened in Brazil to make it the world leader in the use, and in expenditure on, biomass energy and applied biotechnology. Government expenditure is over one billion (US) dollars per year with the aim of producing about five billion litres of alcohol in 1983 and ten billion litres by 1987. About 360 new distilleries are either built or in the planning and construction phase. All of this effort is to try to reduce the annual $\$ 10$ billion cost of imported oil to run a transport system in a vast country which has few rail links. This oil cost still accounts for over half of Brazil's total export income.

Such a crash programme has inevitably given rise to problems - as one Brazilian bureaucrat has remarked, "Any country that spends $\$ 5$ billion on one programme in 8 years is bound to make mistakes". Nevertheless the authors of this book are very frank in thcir appraisal of the programme and what efforts are being made to counteract the most obvious problems. 't helps that one of the authors is a Brazilian research associate and considerable efforts have becn made to use Brazilian source material. However, this is a very rapidly changing field so that with the inevitable delays in book production, the policies and publications of the last 18 months can only be given a three-page summary at the end of the text.

The various problems - land and wealth distribution, pollution, employment, food production, industrial and agricultural policies, local and international financing, costs of production, energy ratios, efficiencies of fermentation, ethanol for the chemical industry and for export - are all covered, though to varying degrees of satisfaction depending on one's biases. The technology of conversion of sugarcane into alcohol is very thoroughly considered, as befits the expertise of one of the authors. However, although it is acknowledged that the production of the feedstock - the sugarcane itself - represents $50 \%$ or more of the total cost of the ethanol produced, it is this production phase which is virtually ignored in the book (presumably because it is assumed that so much is already known about the growing of sugarcane and about sugar production). It is recognized that Brazilian yields on average are low (and the conversion efficiencies to alcohol also low) so that a doubling of yields of alcohol per hectare per year should be achievable, thus altering final costs and energy ratios considerably.

Publicity for Energy from Alcohol suggests that it is the "first full account of Brazil's development of the alcohol industry, drawing upon many sources unavailable in English"'. While fully recommending the book, ! wouldn't totally agree with this claim. There are a number of important references in English by Brazilian authors and agencies which are not mentioned. Also many readers will find at least a third of the references to be untraceable, and these are nearly all to English-language publications. One can also niggle about some confusing use of terms - gallons ('mperial or US?), dollars in 1980 value or not, gasoline $=$ petrol and not petroleum?, and so on. However, this is compensated for by the useful appendices containing data about Brazil, the properties of alcohol and its blends, and addresses of commercial and government agencies. There is also a useful author and subject index.

The Brazilian experience is unique and is certainly "instructive not only to the industrial nations but to those of the Third World", though this is also true of Zimbabwe and the United States. Nonetheless the Brazilians have by far the highest expenditure for importing and exporting both hardware and technological expertise and have approached the energy problems mostly on their own, much to the scepticism of the rest of the world. They are to be congratulated for such pioneering spirit.

D.O. Hall is a Professor in the Department of Plant Sciences at King's College London. 